Senthilkumaran et al. $\quad 1$

\title{
INSULIN-RESPONSIVE AUTONOMIC NEURONS IN RAT MEDULLA OBLONGATA
}

\author{
M Senthilkumaran ${ }^{1,2}$, L Bobrovskaya ${ }^{2}$, A J M Verberne ${ }^{3}$ and I J Llewellyn-Smith ${ }^{1}$ \\ ${ }^{1}$ Cardiovascular Medicine, Human Physiology and Centre for Neuroscience, \\ College of Medicine and Public Health, Flinders University, Bedford Park SA Australia, \\ ${ }^{2}$ School of Pharmacy and Medical Sciences, University of South Australia, Adelaide SA, \\ Australia and ${ }^{3}$ Clinical Pharmacology and Therapeutics Unit, Department of Medicine - \\ Austin Health, University of Melbourne, Heidelberg VIC Australia
}

Text Pages: $\quad 46$

Figures: $\quad 13$

Tables: $\quad 2$

Running Head: Insulin-responsive neurons in rat medulla

\author{
Associate Editor: Paul E. Sawchenko \\ Neuroendocrine Control and Chemical Neuroanatomy \\ Laboratory of Neuronal Structure and Function \\ The Salk Institute for Biological Studies \\ P.O. Box 85800 \\ San Diego, CA 92186
}

This is the author manuscript accepted for publication and has undergone full peer review but has not been through the copyediting, typesetting, pagination and proofreading process, which may lead to differences between this version and the Version of Record. Please cite this article as doi: $10.1002 / \mathrm{cne} .24523$

This article is protected by copyright. All rights reserved. 
*Correspondence to: Prof I.J. Llewellyn-Smith, Department of Medicine, Flinders

Medical Centre, Bedford Park, South Australia 5042 Australia. Telephone: 61-8-8204-4456;

Fax: 61-8-8204-5268; E-mail: ida.llewellyn-smith@flinders.edu.au.

This article is protected by copyright. All rights reserved. 


\section{ACKNOWLEDGMENTS}

Grant Support: Grants from the National Health \& Medical Research Council of Australia to AJMV and ILS (Project Grant \#1025031) 


\section{ABSTRACT}

Low blood glucose activates brainstem adrenergic and cholinergic neurons, driving adrenaline secretion from the adrenal medulla and glucagon release from the pancreas. Despite their roles in maintaining glucose homeostasis, the distributions of insulin-responsive adrenergic and cholinergic neurons in the medulla are unknown. We fasted rats overnight and gave them insulin (10 IU/kg i.p.) or saline after 2 weeks of handling. Blood samples were collected before injection and before perfusion at $90 \mathrm{~min}$. We immunoperoxidase-stained transverse sections of perfused medulla to show Fos plus either phenylethanolamine Nmethyltransferase (PNMT) or choline acetyltransferase (ChAT). Insulin injection lowered blood glucose from $4.9 \pm 0.3 \mathrm{mmol} / \mathrm{L}$ to $1.7 \pm 0.2 \mathrm{mmol} / \mathrm{L}$ (mean+SEM; $\mathrm{n}=6$ ); saline injection had no effect. In insulin-treated rats, many PNMT-immunoreactive C1 neurons had Fosimmunoreactive nuclei, with the proportion of activated neurons being highest in the caudal part of the C1 column. In the rostral ventrolateral medulla, $33.3 \% \pm 1.4 \%(n=8)$ of $\mathrm{C} 1$ neurons were Fos-positive. Insulin also induced Fos in $47.2 \% \pm 2.0 \%(n=5)$ of dorsal medullary C3 neurons and in some C2 neurons. In the dorsal motor nucleus of the vagus (DMV), insulin evoked Fos in many ChAT-positive neurons. Activated neurons were concentrated in the medial and middle regions of the DMV beneath and just rostral to the area postrema. In control rats, very few $\mathrm{C} 1, \mathrm{C} 2$ or $\mathrm{C} 3$ neurons and no DMV neurons were Fos-positive. The high numbers of PNMT-immunoreactive and ChAT-immunoreactive neurons that express Fos after insulin treatment reinforce the importance of these neurons in the central response to a decrease in glucose bioavailability. 
Key Words: Blood glucose, C1 neurons, C3 neurons, dorsal vagal motor neurons, Fos, RVLM, RRID:AB_2231996, RRID:AB_2079751, RRID:AB_2340593, RRID:AB_262016, RRID:AB_2340397 


\section{INTRODUCTION}

Insulin therapy in patients with type 1 and advanced type 2 diabetes often leads to hypoglycemia for many reasons, including doses that are excessive or inaccurately timed (Cryer, 2014). In these patients, the counterregulatory response to hypoglycemia, which includes release of the hormones, glucagon and adrenaline, becomes impaired soon after insulin treatment begins (Arbelaez et al., 2014; Siafarikas et al., 2012). Eventually, the glucagon response is lost, eliminating a first line of defense against hypoglycemia (Bolli et al., 1983; Cryer et al., 2009; Gerich, Langlois, Noacco, Karam, \& Forsham, 1973). At that point, the adrenaline secretory response from the adrenal medulla becomes critical for limiting the development of insulin-induced hypoglycemia.

Results from physiological and anatomical studies have clarified the central and peripheral nerve pathways that control the counterregulatory response to hypoglycemia (Verberne, Korim, Sabetghadam, \& Llewellyn-Smith, 2016; Verberne, Sabetghadam, \& Korim, 2014). Adrenergic chromaffin cells in the medulla of the adrenal gland release adrenaline in response to hypoglycemia (Vollmer et al., 1992). Central output from a distinct set of sympathetic preganglionic neurons (SPN) in the spinal cord regulates secretion of catecholamines from the chromaffin cells (Morrison \& Cao, 2000). Spinally-projecting adrenergic neurons in the rostral ventrolateral portion of the medulla oblongata (RVLM), innervate the sympathoadrenal SPN, playing a crucial role in the adrenomedullary response to a decrease in blood sugar. Like adrenaline-secreting chromaffin cells, C1 neurons are characterized anatomically by the presence of the adrenaline-synthesizing enzyme, phenylethanolamine N-methyltransferase (PNMT), in their cytoplasm. After glucoprivation evoked by the non-metabolizable glucose analogue, 2-deoxyglucose (2DG), both bulbospinal C1 neurons in the RVLM and forebrain-projecting C1 neurons in the caudal medulla express Fos, the nuclear marker of activation (Parker, Kumar, Lonergan, McMullan, \& Goodchild, 
2015; Ritter, Llewellyn-Smith, \& Dinh, 1998). Nevertheless, it is stimulation of the RVLM that activates adrenal sympathetic nerves (Mueller, Mischel, \& Scislo, 2011) and disinhibition of the RVLM with a GABA receptor antagonist that causes an increase in blood glucose level (Verberne \& Sartor, 2010). In support of an essential role for spinally-projecting C1 RVLM neurons, their destruction with a saporin-based neurotoxin almost abolishes the adrenaline release evoked by glucoprivation (Madden, Stocker, \& Sved, 2006; Ritter, Bugarith, \& Dinh, 2001). In contrast, elimination of forebrain-projecting C1 neurons in the caudal medulla eliminates glucoprivic feeding (Hudson \& Ritter, 2004; Li, Wang, \& Ritter, 2011; Ritter, Dinh, \& $\mathrm{Li}, 2006)$. Although all these findings indicate that the $\mathrm{C} 1$ neurons are indispensable for blood glucose regulation, the distribution of $\mathrm{C} 1$ neurons that respond to insulin-induced hypoglycemia has not been characterized.

There is also evidence that the other two groups of adrenergic neurons in the medulla oblongata, C2 adrenergic neurons in the nucleus of the solitary tract (NTS) and C3 neurons in the dorsomedial medulla, respond to changes in glucose bioavailability. Glucose deprivation induced by administration of either 2DG (Ritter et al., 1998) or insulin (Yuan \& Yang, 2002) increases the number of Fos-immunoreactive C2 neurons. The firing rates of presumptive catecholamine neurons in the NTS also change when blood glucose levels change (Yettefti, Orsini, \& Perrin, 1997). Like C2 neurons, C3 neurons are activated by 2DGinduced glucoprivation (Menuet et al., 2014; Ritter et al., 1998). Amongst the population of C3 neurons, there are spinally-projecting neurons that innervate SPN and neurons that supply medullary nuclei including the NTS, RVLM and caudal ventrolateral medulla (CVLM) as well as neurons that send axons rostrally to higher brain centers involved in glycemic control, such as the hypothalamus (Sevigny et al., 2012). Despite the possible involvement of C3 neurons in blood glucose regulation, whether or not these neurons are activated by insulin-induced hypoglycemia has never been investigated. 
As well as causing adrenaline release, insulin-induced hypoglycemia in humans stimulates the vagus to increase secretion from the pancreas and gall bladder (Smith, Edwards, \& Johnston, 1981). The pancreatic effect is likely due to activation of cholinergic vagal motor neurons that lie in the dorsal motor nucleus of the vagus (DMV) and regulate the release of hormones, including insulin and glucagon (Mussa \& Verberne, 2013). Fos immunohistochemistry has shown that neurons in the DMV are activated in response to insulin-induced hypoglycemia and that some of them are immunoreactive for choline acetyltransferase (ChAT), the enzyme that synthesizes acetylcholine (Yuan \& Yang, 2002). However, the distribution of the medullary cholinergic neurons activated in response to insulin-induced hypoglycemia is still unclear.

The data summarized above show that changes in the bioavailability of glucose affect the activity of all three groups of medullary adrenergic neurons and of cholinergic neurons in the DMV. Nevertheless, we know of no studies examining the distributions of $\mathrm{C} 1$ and $\mathrm{C} 3$ neurons or vagal motor neurons that are activated by insulin-induced hypoglycemia. To fill this gap in knowledge, we used two-color immunoperoxidase staining for Fos and neurochemical markers of adrenergic or cholinergic neurons on medulla sections from rats that had been given a single injection of either insulin or vehicle. We demonstrate that, while saline has no effect, hypoglycemia caused by insulin activates significant fractions of medullary adrenergic $\mathrm{C} 1$ and $\mathrm{C} 3$ neurons as well many of the cholinergic neurons in the DMV. We also define the distributions of these insulin-responsive neurons within the medulla.

\section{METHODS}

All animal experiments in this study were approved by the Animal Welfare Committee of Flinders University (Australia). The School of Medicine Animal Facility at Flinders 
University provided male Sprague Dawley rats $(n=44)$ at 6-8 weeks of age. Rats were maintained with a $12 \mathrm{hr}$ light:dark cycle and had access to food and water ad libitum. They were handled twice a day for two weeks before the commencement of experimentation to reduce handling-related stress.

\subsection{Effects of Insulin on blood glucose levels}

To establish the effects of insulin on blood glucose, one set of rats $(n=16)$ were given insulin (10 U/kg in saline) or saline via intraperitoneal injection after an overnight fast. In all experiments, rats were not anaesthetized for the injection because administration of isoflurane through a nose cone induced stress-related Fos expression in C1 neurons in the caudal ventrolateral medulla (CVLM) in control rats (data not shown). Blood glucose was measured using a handheld glucometer (Accu-chek Performa, Roche Diagnostics, Germany) from a drop of blood obtained through a tail vein prick. Tail vein blood glucose levels were measured 5 min before the injection of insulin or saline and then at 30,60 and 90 min after injection.

\subsection{Tissue preparation for Fos immunohistochemistry}

A separate set of rats $(n=28)$ were used for studying Fos expression in response to insulin-induced hypoglycemia. On the evening before the experiment, rats were transferred to individual cages and fasted overnight with free access to water. They then received an intraperitoneal injection of either insulin (10 U/kg in saline) or saline. In this part of the study, tail vein blood glucose was measured 5 min before the injection of insulin or saline and then at 90 min, which was just before perfusion. Blood glucose measurements were not taken at 30 and 60 min in these rats to avoid the stress caused by tail vein prick, which increased Fos expression in caudal C1 neurons in both insulin-treated and saline-treated rats.

This article is protected by copyright. All rights reserved. 
Immediately after the measurement of blood glucose at $90 \mathrm{~min}$, rats were anaesthetized with an intraperitoneal injection of Lethabarb (Virbac Pty Limited, Milperra, Australia), which had been diluted to $60 \mathrm{mg} / \mathrm{ml}$ with water, at a dose of $90 \mathrm{mg} / \mathrm{kg}$ pentobarbitone sodium. Rats were checked periodically for pedal reflexes. When the rat was unresponsive, its abdominal cavity was opened via a midline incision. The renal arteries and the intestines were clamped with haemostats. The xiphoid process was held with another haemostat; the diaphragm was opened and the ribs divided to expose the heart. A blunt beveled needle was inserted into the ascending aorta through the left ventricle. One $\mathrm{ml}$ of heparin (1000 IU/ml; Hospira, Melbourne, Australia) was administered through a three-way tap to prevent blood clotting. The right atrium was then snipped and blood was flushed from the rat's vasculature with $500 \mathrm{ml}$ of DMEM/F12 culture medium (Dulbecco's modified Eagle's medium, Catalogue \# D8900, Sigma-Aldrich, St Louis, USA). The rat was then perfused with 1 litre of $4 \%$ formaldehyde in $0.1 \mathrm{M}$ phosphate buffer, $\mathrm{pH} 7.4$. Formaldehyde solution (min. 37\%; Catalogue \# 10400310000, Merck Millipore, Victoria, Australia) was used to prepare the fixative. After perfusion, the brain and adrenal glands were collected and post-fixed in the same fixative solution for 3-5 days at room temperature on a shaker. Blocks containing the brainstem were then trimmed from the post-fixed brains using a brain matrix (Braintree Scientific, Braintree, MA USA).

After post-fixation, 2 to 3 adrenal glands from insulin-treated rats were embedded together with 1-2 adrenal glands from saline-treated rats in albumin-gelatine (Llewellyn-Smith et al., 2007). Medullas and the adrenal glands that had been embedded in albumin-gelatine were infiltrated with $20 \%$ then $30 \%$ sucrose and were cut into 4 series of $30 \mu \mathrm{m}$ coronal sections using a cryostat. 


\subsection{Immunohistochemistry}

In all immunohistochemistry experiments, sections were initially washed $3 \times 10$ min with $10 \mathrm{mM}$ Tris, $0.9 \% \mathrm{NaCl}, 0.05 \%$ thimerosal in $10 \mathrm{mM}$ phosphate buffer, $\mathrm{pH} 7.4$, (TPBS) containing $0.3 \%$ Triton X-100 and then treated with 10\% normal horse serum (NHS; Gibco Heat-Inactivated Horse Serum; Life Technologies, Mulgrave, Australia) in TPBS-Triton for 30 min to prevent non-specific antibody binding. TPBS-Triton containing $10 \%$ NHS was used as the diluent for primary antibodies; TPBS-Triton containing 1\% NHS was used as the diluent for secondary antibodies and TPBS-Triton was used as the diluent for the ExtrAvidinperoxidase complex. In all experiments, the sections were incubated in immunoreagents at room temperature with constant agitation on a shaker and were washed $3 \times 10$ min with TPBS after each incubation. After immunostaining was complete, sections were mounted in serial order on slides coated with chrome alum-gelatine, dried and coverslipped with Permaslip mounting medium (Catalogue \# A325A, Alban Scientific Inc, St Louis MO, USA).

\section{Double immunoperoxidase staining for Fos and PNMT: We did double}

immunoperoxidase staining for Fos and PNMT on one series of sections from a 1:4 series of sections of adrenal glands from each of 6 insulin-treated rats and each of 6 saline-treated rats. We stained 1 series of sections from a 1:4 series of sections of medulla oblongata from each of 15 insulin-treated rats and each of 13 saline-treated rats similarly. After exposure to $10 \%$ NHS-TPBS-Triton, sections were incubated in a 1:5,000 dilution of rabbit anti-Fos antibody (Table 1; RRID:AB_2231996; Santa Cruz Biotechnology, Dallas, Texas, USA) for 34 days. After washing in TPBS, the sections were incubated overnight in a 1:500 dilution of biotinylated donkey anti-rabbit immunoglobulin (RRID:AB_2340593; Catalogue \#711-065152, Jackson ImmunoResearch Laboratories, West Grove, PA, USA) followed by incubation for 4-6 hours in a 1:1,500 dilution of ExtrAvidin-horseradish peroxidase complex (RRID:AB_2620165; Catalogue \# E-2886, Sigma Aldrich, St Louis, MO, USA). A 
diaminobenzidine (DAB) reaction intensified with cobalt and nickel (Llewellyn-Smith, DiCarlo, Collins, \& Keast, 2005) was then carried out, yielding a black reaction product in Fosimmunoreactive nuclei. After Fos detection, the sections were blocked again for $30 \mathrm{~min}$ in $10 \%$ NHS-TPBS-Triton and then incubated in a 1:30,000 dilution of a rabbit anti-PNMT antibody (Table 1; no RRID available; kind gift from Dr Luc Denoroy) for 3-4 days. After washing, the sections were incubated overnight in a 1:500 dilution of biotinylated donkey anti-rabbit immunoglobulin and then for 4-6 hours in 1:1,500 ExtrAvidin-horseradish peroxidase complex. An imidazole-intensified DAB reaction (Llewellyn-Smith et al., 2005) was carried out to achieve a brown reaction product in cells containing PNMTimmunoreactivity.

Double immunoperoxidase staining for Fos and ChAT: Another 1:4 series of medulla sections from 9 insulin-treated rats and 5 saline-treated rats were double stained for Fos and ChAT. The sections were initially stained for Fos as described above. After a second blocking step with 10\% NHS-TPBS-Triton, the sections were incubated in a 1:2,000 or 1:5,000 dilution of goat anti-ChAT antibody (Table 1; RRID:AB_2079751; Chemicon, Temecula, CA, USA) for 3-4 days. After washing as above, the sections were incubated overnight in a 1:500 dilution of biotinylated donkey anti-goat immunoglobulin (RRID:AB_2340397; Catalogue \# 705-065-147; Jackson ImmunoResearch Laboratories) and then for 4-6 hours in ExtrAvidin-horseradish peroxidase complex. An imidazoleintensified DAB reaction (Llewellyn-Smith et al., 2005) produced a brown reaction product in neurons that contained ChAT-immunoreactivity.

\subsection{Antibody Characterization}

For each different combination of primary and secondary antibodies, titrations were performed to optimize specific staining and minimize non-specific background labelling. 
Some of the earliest publications using the rabbit anti-Fos antibody from Santa Cruz Biotechnologies (SCBT; Catalogue \# sc-253, also known as K25) state that the antibody was raised against the highly conserved amino acids $128-152$ of the protein produced by the human c-fos gene (Pierce, Sandefur, Doyle, \& Welgus, 1996; Wargnier et al., 1995; Welter, Crish, Agarwal, \& Eckert, 1995). Amino acids 128-152 occur within the region of human Fos protein (amino acids 125-175) that SCBT told us contains the antigen against which sc-253 antibody was raised. We have previously shown that immunostaining for Fos is eliminated by overnight absorption of the Santa Cruz rabbit anti-Fos sc-253 with the peptide against which it was raised (Fenwick, Martin, \& Llewellyn-Smith, 2006). Western blotting performed by SCBT on lysates of human transfected cells showed very intense bands at molecular weights corresponding to the protein products of $c$-fos and FosB and a moderately intense band at a molecular weight corresponding to the protein product of FRA2. No information was provided about cross-reactivity with the protein product of FRA1. In further confirmation of the specificity of sc-253, we have found that this antibody shows a distribution of 2DGactivated C1 and C3 neurons in rats (Korim, Llewellyn-Smith, \& Verberne, 2016; Menuet et al., 2014) that is very similar to the distribution of 2DG-responsive neurons localized with an Arnel anti-Fos antiserum that we have used previously (Ritter et al., 1998) and to the distribution detected by others with a different SCBT anti-Fos that was raised against amino acids 3-16 of the protein encoded by human c-fos (Parker et al., 2015; Parker et al., 2017). Staining with SCBT anti-Fos Sc-253 also reveals virtually the same distribution of hypotension-responsive C1 neurons in normotensive WKY rats as our sheep anti-Fos (Minson, Arnolda, Llewellyn-Smith, Pilowsky, \& Chalmers, 1996) and produces a similar staining pattern to other anti-Fos antisera that have been used for functional neuroanatomical studies on barosensitive C1 neurons in rats (e.g., (Chan \& Sawchenko, 1998; Stornetta, Sevigny, Schreihofer, Rosin, \& Guyenet, 2002; Sved, Mancini, Graham, 
Schreihofer, \& Hoffman, 1994). CiteAb shows that SCBT anti-Fos Sc-253 has been cited in 274 publications (https://www.citeab.com/antibodies/790368-sc-253-c-fos-antibody-k-25). We have used this antibody in five of our previous publications (Burman, Sartor, Verberne, \& Llewellyn-Smith, 2004; Fenwick et al., 2006; Korim et al., 2016; Llewellyn-Smith, Kellett, Jordan, Browning, \& Travagli, 2012; Menuet et al., 2014), two of which appeared in the Journal of Comparative Neurology.

Dr Luc Denoroy raised the anti-PNMT antibody in rabbits and provided us with several lyophilized aliquots. Absorption of this antibody with purified bovine PNMT has previously been show to abolish staining in the medulla (Carlton, Honda, Denoroy, \& Willis Jr, 1987). This antibody has also been used extensively to identify adrenergic neurons in the brains of a variety of species, including rat and human (Carlton, Honda, \& Denoroy, 1989; Garcia, Denoroy, Le Cavorsin, Pujol, \& Weissmann, 1996; Kitahama, Denoroy, Berod, \& Jouvet, 1986; Kitahama et al., 1985; Mittendorf, Denoroy, \& Flugge, 1988; Siaud, Denoroy, Assenmacher, \& Alonso, 1989). In this study, we found that the antibody showed the expected distribution of PNMT-immunoreactive cell bodies in the rat medulla.

Sections of rat spinal cord stained with the goat anti-ChAT antiserum show the expected distribution of cholinergic neurons in the spinal cord (Fenwick et al., 2006) and, as we found here, in the medulla. When we used recombinant rat ChAT to adsorb this antiserum, we found no staining in tissue fixed and processed as done here (Llewellyn-Smith et al., 2005).

\subsection{Data Analysis}

Counting insulin-responsive RVLM C1 neurons: Images of the immunostained sections were captured using an Olympus $\mathrm{BH} 2$ brightfield microscope and a SPOT Insight Model 18.2 firewire colour camera running SPOT RT software v5.2 (Diagnostic Instruments, 
Inc., Sterling Heights, MI, USA). Overlapping digital images of RVLM on one side of the brainstem from each of 8 insulin-treated rats and each of 8 saline-treated rats were captured using a 10x objective and saved as TIFF files. The TIFF files were then imported into Adobe PhotoShop CS6 and montaged to create a single image of the region for counting. A box measuring $1.3 \mathrm{~mm} \times 0.8 \mathrm{~mm}$ that had been previously prepared in PhotoShop was added to the montage as an additional layer and the medial end of the box was aligned to the lateral edge of the pyramid. To include the entire mediolateral extent of the region in the ventrolateral medulla that contained PNMT-immunoreactive neurons, the lateral side of the box was adjusted to be $0.2 \mathrm{~mm}$ lateral to the most lateral PNMT-immunoreactive neuron. We classified neurons as Fos-positive and PNMT-positive (i.e., Fos/PNMT neurons) or as Fosnegative, PNMT-positive (i.e., PNMT only neurons) by examining each neuron at $x 40$ magnification with the $\mathrm{BH} 2$ microscope. For recording Fos/PNMT neurons, we added a new layer to the montage in PhotoShop and then used the pencil tool to mark Fos/PNMT neurons with red dots on this layer. For recording PNMT only neurons, another new layer was created and PNMT only neurons were marked with blue dots on this layer using the pencil tool. Each layer containing dots was then converted to grayscale and saved as a TIFF file. The grayscale images were opened in ImageJ (Schindelin et al., 2012). The dots in each image were counted using the Analyze Particles function and the counts were recorded in an excel file for subsequent analysis.

Counting insulin-responsive C3 neurons: The dorsomedial medulla from 5 insulintreated rats and 5 saline-treated rats were photographed and montages of digital images were created as described above. Two new layers were then added in PhotoShop and the Fos/PNMT and PNMT only neurons were marked with red and blue dots, respectively. The layers with red dots and the layer with blue dots were saved separately, converted to gray scale and counted using ImageJ as described above. 
Maps of insulin-responsive neurons: The method for constructing maps showing the locations of insulin-responsive neurons in the RVLM and DMV was similar to that we have used previously (Llewellyn-Smith, Gnanamanickam, Reimann, Gribble, \& Trapp, 2013). Every fourth $30 \mu \mathrm{m}$-thick section double-stained for Fos plus PNMT or Fos plus ChAT was mapped; hence, $90 \mu \mathrm{m}$ separated mapped sections. To make line drawings, micrographs were taken of the RVLM or DMV in each section at $\times 10$ magnification and montaged as described above. On separate layers added to the montages in PhotoShop, the pen tool was used to trace the surface of the medulla and internal anatomical landmarks. Low magnification line drawings of each section were created from digital images taken at $x 2$ using a similar strategy. To record the location of each PNMT- or ChAT-immunoreactive neuron on a line drawing, a separate layer was added to the TIFF file containing the montage of each section. The position of each neuron was marked with a dot using the pencil tool, with red dots for Fos/PNMT or Fos/ChAT neurons and blue dots for PNMT only or ChAT only neurons. The red and blue dots were counted as described above. For the RVLM map in Figure 5, a total of 8 sections were mapped from FN-5 (600 $\mu$ m caudal to FN0) to FN+2 (240 $\mu \mathrm{m}$ rostral to FN0). For the DMV map in Figure 11, a total of 13 sections were mapped starting at the caudal tip of the area postrema (AP0) and extending rostrally for 12 sections to about $1 \mathrm{~mm}$ from where the central canal opened into the fourth ventricle. Plates containing the individual maps for each section were prepared in PhotoShop.

Statistical analyses: We used PRISM v6.05 software (GraphPad Software, Inc., USA) for statistical analysis of our quantitative data. We performed a Student's $t$ test to determine the effects of treatment on blood glucose levels and Mann-Whitney tests to determine the effects of treatment on the total numbers of neurons in different adrenergic neuronal populations. To compare the effects of treatment on the numbers of Fos/PNMT and PNMT 
only neurons in different sections, we carried out two-way ANOVA with repeated measures and a Bonferroni post hoc test. Data are presented as mean $\pm \mathrm{SEM} ; P<0.05$ was considered statistically significant.

\section{RESULTS}

\subsection{Effect of insulin on blood glucose}

The effect of a single intraperitoneal injection of $10 \mathrm{U} / \mathrm{kg}$ insulin or saline on blood glucose was tested in rats in which blood glucose levels were measured just before injection and at 30,60 and 90 min after injection (Figure 1). Insulin treatment produced a statistically significant lowering of blood glucose from $5.1 \pm 0.2 \mathrm{mmol} / \mathrm{L}$ at baseline to $1.6 \pm 0.1 \mathrm{mmol} / \mathrm{L}$ at 90 min after insulin administration (mean \pm SEM; $n=9 ; P<0.001$ ) whereas saline treatment had no effect $(4.7 \pm 0.1 \mathrm{mmol} / \mathrm{L}$ at baseline vs $5.0 \pm 0.2$ at $90 \mathrm{~min} ; \mathrm{n}=7 ; P=0.93)$.

To minimize the possibility of Fos induction by stress, only two blood glucose measurements were made in the rats that were used for studies to identify insulin-responsive autonomic neurons, i.e., a baseline measurement just before insulin or saline injection and one measurement just before perfusion at 90 min after treatment. In the rats receiving insulin $(\mathrm{n}=15)$, blood glucose was $5.4 \pm 0.1 \mathrm{mmol} / \mathrm{L}$ at baseline and declined to $1.6 \pm 0.1 \mathrm{mmol} / \mathrm{L}$ at $90 \mathrm{~min}$, a change that was statistically significant $(P<0.001)$. In the rats receiving saline ( $\mathrm{n}=13$ rats), baseline blood glucose was $4.8 \pm 0.2 \mathrm{mmol} / \mathrm{L}$ and the value at 90 minutes was $4.9 \pm 0.3 \mathrm{mmol} / \mathrm{L}$, showing that saline had no effect $(P=0.91)$.

\subsection{Insulin-responsive chromaffin cells in the adrenal medulla}

Sections through the adrenal glands of 6 insulin-treated and 6 saline-treated rats were double-stained to reveal Fos, a nuclear marker of chromaffin cell activation (Parker, Kumar, Lonergan, \& Goodchild, 2013; Ritter, Scheurink, \& Singer, 1995), and PNMT to 
discriminate adrenaline-synthesizing chromaffin cells from noradrenaline-synthesizing chromaffin cells (Figure 2). This double labelling protocol revealed that almost all the PNMTimmunoreactive chromaffin cells in insulin-treated rats had Fos-immunoreactive nuclei (Figure 2a) whereas, in saline-treated control rats, none of the PNMT-positive cells had Fospositive nuclei (Figure 2b).

\subsection{Distribution of insulin-responsive autonomic neurons}

C1 Neurons: A 1:4 series of $30 \mu \mathrm{m}$-thick sections of medulla from each of 12 insulintreated rats and from each of 10 saline-treated control rats that had been double labelled for Fos as a marker of neuronal activation and PNMT as a marker of adrenergic neurons were analyzed for the distribution of insulin-responsive C1 neurons. Brown, PNMTimmunoreactive $\mathrm{C} 1$ neurons in the ventral medulla first appeared caudally at the level of the area postrema and formed a continuous column that ended rostrally several hundred micrometers past the caudal end of the facial nucleus (FN). The PNMT-positive neurons were located lateral to the pyramids and ventral to the nucleus ambiguus until it disappeared near where FN began. In sections containing FN, PNMT-immunoreactive neurons were located medial and ventral to this structure.

Many of the brown PNMT-immunoreactive neurons in the ventral medulla had black Fos-immunoreactive nuclei after insulin treatment, revealing that insulin-induced hypoglycemia activated C1 neurons. Fos/PNMT neurons were distributed bilaterally. Activated C1 neurons were first encountered at the caudal end of the C1 cell column and extended rostrally past the caudal pole of FN. The vast majority of Fos/PNMT neurons were located caudal to the caudal pole of the FN (Figures 3 and 4), with very few Fos/PNMT neurons occurring rostral to that point. Within the roughly 500 micrometer portion of the $\mathrm{C} 1$ cell column immediately caudal to FN, there appeared to be a trend for insulin-responsive $\mathrm{C} 1$ 
neurons to be located closer to the pyramids in the medial and middle portions of the $\mathrm{C} 1$ column rather than in the lateral portion of the column (Figure 5).

In rats treated with saline (Figure 6), brown PNMT-immunoreactive neurons that had black Fos-immunoreactive nuclei were very rare throughout the $\mathrm{C} 1$ column. These rare Fos/PNMT neurons occurred in both rostral and caudal parts of the C1 column.

Non-C1 neurons in RVLM: We also examined the RVLM sections stained for Fos and PNMT to determine whether Fos-immunoreactive nuclei that were not contained within PNMT-immunoreactive cell bodies were present. Fos-positive/PNMT-negative neurons occurred in the RVLM of all insulin-treated and all saline-treated rats. Within each of these treatment groups, the numbers of insulin-responsive non-C1 varied markedly between rats.

C2 Neurons: The cell bodies of PNMT-immunoreactive C2 neurons occurred bilaterally within the NTS and extended from the level of the rostral part of the area postrema (AP) to the level containing the caudal pole of FN. Some of the PNMT-positive neurons in the NTS were Fos-positive in the insulin-treated rats (Figure 7), indicating that the C2 neurons were also activated by insulin-induced hypoglycemia. The Fos-positive C2 neurons started to appear at a level near to the rostral end of the AP and they extended for about $1.6-1.7 \mathrm{~mm}$ rostral to that point.

In saline-treated control rats, there were a few PNMT-positive C2 neurons that were Fos-positive.

C3 Neurons: PNMT immunostaining revealed that the C3 neurons, the third set of adrenergic neurons in the medulla oblongata, occurred in the dorsal medulla around the midline and spread bilaterally almost to the solitary tract. C3 cell bodies started to appear at the level of the AP and extended rostrally for about $1.7 \mathrm{~mm}$. Insulin-induced hypoglycemia activated C3 neurons (Figure 8). Fos/PNMT neurons were identified throughout the C3 cell 
column, including a few Fos-positive PNMT neurons located at the caudal and rostral ends of the column.

In control rats treated with saline (Figure 9), rare PNMT-immunoreactive C3 neurons had Fos-immunoreactive nuclei.

DMV Neurons: The distribution of insulin-responsive cholinergic neurons in the DMV was assessed in another 1:4 series of $30 \mu \mathrm{m}$ medulla sections that had been double labelled for Fos as a marker of activation and ChAT as a marker of cholinergic neurons from 9 insulin-treated rats and 5 saline-treated rats. In the dorsal medulla, the ChATimmunoreactive neurons of the DMV formed compact clusters bilaterally dorsal to the hypoglossal nucleus and extended from sections near the spinomedullary junction caudally up to sections containing the rostral end of the compact formation of the nucleus ambiguus. A high proportion of the ChAT-positive DMV neurons had Fos-positive nuclei after injection of insulin (Figure 10).

Figure 11 maps the rostrocaudal distribution of Fos/ChAT neurons and ChAT only neurons in the DMV of one insulin-treated rat from the caudal tip of the area postrema (AP0) for about $1.7 \mathrm{~mm}$ rostrally. In the mapped region in this rat, there were a total of $808 \mathrm{ChAT}$ immunoreactive neurons, of which 279 (35.4\%) had Fos-immunoreactive nuclei. The maps for each section reveal that the Fos/ChAT neurons tended to occur in the medial and middle portions of the DMV and were only rarely found in the most lateral DMV region. Whilst there were a few Fos/ChAT neurons in the DMV caudal to the AP (not shown), the regions of the DMV beneath and rostral to the area postrema contained the vast majority of the neurons that were activated to express Fos by insulin treatment (Figure 11). The highest proportion of activated DMV neurons occurred in sections at and just caudal to the rostral edge of the area postrema (i.e., at sections $+600 \mu \mathrm{m}$ and $+720 \mu \mathrm{m}$ rostral to AP0 in Figure 11 ), where about half of the ChAT-positive neurons were also Fos-positive. 
In sections from the insulin-treated rats stained for Fos plus ChAT, the DMV contained occasional Fos-immunoreactive nuclei that were not located within ChATimmunoreactive cell bodies, i.e. Fos-positive/ChAT negative neurons.

In saline-treated rats (Figure 12), none of the ChAT-positive DMV neurons contained Fos-positive nuclei. Fos-immunoreactive non-cholinergic neurons were also absent from the DMV of saline-treated rats.

\subsection{Quantification of insulin-responsive RVLM C1 neurons}

We counted PNMT-immunoreactive neurons in which insulin did or did not induce Fos expression only in the RVLM because our main interest is in C1 neurons that mediate the glucose counterregulatory response (Damanhuri et al., 2012; Verberne \& Sartor, 2010). These neurons occur in the rostral part of the C1 column, i.e., the RVLM, and their spinallyprojecting axons innervate sympathetic preganglionic neurons that control adrenaline release from adrenergic chromaffin cells in the adrenal medulla. We did not count insulin-responsive C1 neurons in the caudal portion of the $\mathrm{C} 1$ column because they are known to project to the hypothalamus, where they influence feeding behavior (Li, Wang, Elsarelli, Brown, \& Ritter, 2015; Verberne, Stornetta, \& Guyenet, 1999).

In each of 8 insulin-treated control rats and each of 8 saline-treated rats, the number of PNMT-immunoreactive C1 neurons with Fos-immunoreactive nuclei (Fos/PNMT C1 neurons) and PNMT-positive C1 neurons that had Fos-negative nuclei (PNMT only C1 neurons) were counted in 10 serial sections rostral and caudal to FN. The first section through the caudal pole of FN was labelled FNO; sections FN-1 to FN-5 lay caudal to the caudal pole of and sections $\mathrm{FN}+1$ to $\mathrm{FN}+4$, rostral to the caudal pole of FN. Because the sections that were stained and counted were one series from a 1:4 series of $30 \mu \mathrm{m}$-thick 
sections, FNO to FN-5 span the region commonly defined as the RVLM of the rat medulla oblongata, i.e. the 600 micrometers caudal to the caudal pole of FN.

A Mann-Whitney test showed that the total number of PNMT-immunoreactive C1 neurons in the RVLM (i.e., Fos/PNMT neurons + PNMT only neurons in sections FN-5 to $\mathrm{FN}+4)$ was not different in the insulin-treated compared to the saline-treated rats $(214 \pm 5.8$ and $219 \pm 9.7$, respectively; $n=8$ per group; $P>0.9999)$. In the insulin-treated rats, however, an average of $71.6 \pm 4.6$ PNMT-positive neurons had Fos-positive nuclei, which constitutes $33.3 \% \pm 1.4 \%$ of the total PNMT-labelled $\mathrm{C} 1$ population in $\mathrm{FN}-5$ to $\mathrm{FN}+4$. In saline-treated control rats, there were only $24 \pm 4.6$ Fos/PNMT C1 neurons, constituting $10.7 \pm 2.0 \%$ of the total PNMT-stained C1 population in the same region of the ventral medulla. The numbers and percentages of Fos/PNMT neurons in insulin-treated and control rats were significantly different $(P<0.001)$.

We used a two-way ANOVA with repeated measures and a Bonferroni post hoc test to compare the numbers of Fos/PNMT neurons and total numbers of PNMT neurons between insulin-treated rats $(n=8)$ and saline-treated rats $(n=8)$ on a section-by-section basis. This analysis also revealed statistically significant differences. The total number of PNMT-immunoreactive neurons in each section (i.e., Fos/PNMT neurons + PNMT only neurons) was not different between saline-treated and insulin-treated rats ( $P>0.05$; Table 2$)$. However, the numbers of Fos/PNMT neurons (Figure 13) were significantly increased in insulin-treated compared to saline-treated rats in the $600 \mu \mathrm{m}$ caudal to caudal pole of FN (i.e., sections FN-5, FN-4, FN-3, FN-2, FN-1; $P<0.001$ ) and the sections containing the caudal pole of FN (i.e., FN0; $P<0.01$ ). There was a significant interaction between the distance of the sections from FN and the treatment. The number of Fos/PNMT neurons increased gradually from the caudal end of the RVLM (i.e., FN-5, $600 \mu \mathrm{m}$ caudal to FNO). 
The number of Fos/PNMT neurons peaked in FN-2 (240 $\mu \mathrm{m}$ caudal to FN0), rostral to which there was a decline in the number of these neurons. The numbers of Fos/PNMT neurons rostral to the caudal pole of FN were not significantly different between treatments.

\subsection{Quantification of insulin-responsive RVLM non-C1 neurons}

In sections $\mathrm{FN}-5$ to $\mathrm{FN}+4$ from 4 rats that received insulin and 4 rats that received saline, we counted Fos-immunoreactive nuclei that occurred outside of PNMTimmunoreactive nerve cell bodies, i.e. Fos only non-C1 neurons, in the RVLM. In salinetreated rats, the RVLM contained $103.5 \pm 39.2$ (mean \pm SEM; $n=4$ ) Fos only neurons whereas there were $63.8 \pm 16.6(n=4)$ Fos only neurons in the RVLM of insulin-treated rats. A Mann-Whitney test showed that the numbers of Fos only non-C1 neurons in the RVLM did not differ between the two treatment groups $(\mathrm{P}=0.69)$.

\subsection{Quantification of insulin-responsive C3 neurons}

We counted Fos/PNMT neurons and PNMT only neurons through the entire extent of the region that contained $\mathrm{C} 3$ neurons in 5 saline-treated control rats and 5 insulin-treated rats. Counts taken from every 4th $30 \mu \mathrm{m}$ section throughout the C3 region revealed that the total number of PNMT-immunoreactive neurons (i.e., Fos/PNMT neurons + PNMT only neurons) in the insulin-treated rats $(286 \pm 29 ; n=5)$ did not differ from the total number of PNMT-positive neurons in the saline-treated rats $(277 \pm 9 ; n=5 ; P=0.54)$. Insulin treatment activated many of the PNMT-stained C3 neurons. After insulin-induced hypoglycemia, $133 \pm$ $8(n=5)$ PNMT-immunoreactive C3 neurons had Fos-immunoreactive nuclei, constituting $47.2 \% \pm 2.0 \%$ of the total C 3 population. In contrast, in the saline-treated group, only $34 \pm 6$ $(n=5)$ C3 neurons, constituting $12.2 \% \pm 1.9 \%$ of the total C3 neurons, were Fos-positive $(P<0.001)$ 


\section{DISCUSSION}

In this study, using Fos expression as a marker of neuronal activation, we established that $\mathrm{C} 1$ and $\mathrm{C} 3$ adrenergic neurons in the medulla are strongly activated by insulin-induced hypoglycemia. PNMT-positive neurons throughout the C1 cell column were Fos-positive with more Fos/PNMT neurons located in the caudal part of the C1 column than in the RVLM. Nearly half of the C3 neurons also expressed Fos in response to insulin-induced hypoglycemia, with activated neurons distributed throughout the C3 cell column. Finally, insulin treatment evoked Fos expression in a high proportion of the cholinergic neurons in the DMV, with the majority of the Fos/ChAT neurons located in the medial and middle portions of the DMV around the rostral edge of the area postrema.

\subsection{Insulin-responsive adrenergic neurons}

Our finding of insulin-induced activation of C1 neurons is consistent with earlier studies reporting that 2DG-induced glucoprivation increases Fos expression in C1 neurons (Parker et al., 2015; Ritter et al., 1998) and increases discharge of bulbospinal RVLM neurons (Verberne \& Sartor, 2010). Glucoprivation caused by 2DG and hypoglycemia caused by insulin also induce phosphorylation of tyrosine hydroxylase in C1 neurons (Damanhuri et al., 2012; Senthilkumaran, Johnson, \& Bobrovskaya, 2016), further supporting the involvement of these neurons in the physiological response to changes in glucose bioavailability. Fos expression due to 2DG-induced glucoprivation has been previously reported to occur mainly in neurons in the caudal $2 / 3$ of the $\mathrm{C} 1$ cell column (Ritter et al., 1998). In contrast, we found that, after insulin treatment, Fos/PNMT neurons occurred throughout the $\mathrm{C} 1$ cell column, with a high proportion of the PNMT-positive neurons in the CVLM being Fos-positive and about one-third of the PNMT-positive neurons in the RVLM being Fos-positive. A possible reason for this discrepancy in Fos response is that the stimuli 
produced by 2DG and insulin are different in nature. Insulin treatment reduces blood glucose and triggers glucagon and adrenaline release. However, the hypoglycemic condition persist because the blood level of insulin remains high. In contrast, 2DG competes with glucose for binding to glucose-sensing neurons leading to the release of glucagon and adrenaline, resulting in hyperglycemia. Hence, both insulin and 2DG increase the secretion of counterregulatory hormones but only insulin results in hypoglycemia. In addition, we found that few of the PNMT-stained neurons located rostral to the caudal pole of the FN synthesized Fos in response to insulin. Previous studies have shown that a sub-population of $\mathrm{C} 1$ neurons in the caudal part of the C1 cell column that express neuropeptide $\mathrm{Y}$ project rostrally to the hypothalamus (Stornetta, Akey, \& Guyenet, 1999) and destruction of C1 neurons with hypothalamic projections has implicated these neurons in glucoprivic feeding responses ( $\mathrm{Li}$, Wang, Dinh, \& Ritter, 2009; Ritter et al., 2001). Furthermore, C1 neurons do not sense glucose themselves and are more likely to be activated by the orexinergic input from the perifornical region of the hypothalamus (Korim, Bou Farah, McMullan, \& Verberne, 2014). This view is supported by a direct innervation of the RVLM by orexin and melanin concentrating hormone neurons in the perifornical hypothalamus (Kerman et al., 2007) and by the induction of Fos-immunoreactivity in orexin neurons in response to insulin-induced hypoglycemia and 2DG-induced glucoprivation (Briski \& Sylvester, 2001; Cai et al., 2001).

Our data show that C3 adrenergic neurons in the dorsomedial medulla are also strongly activated by insulin-induced hypoglycemia, which is consistent with the observations that they respond to 2DG-induced glucoprivation (Menuet et al., 2014; Ritter et al., 1998). Like Fos expression in C3 neurons in response to insulin-induced hypoglycemia, 2DGinduced Fos occurs in PNMT-positive neurons throughout the C3 cell column (Menuet et al., 2014). The C3 neurons mediate sympathoexcitation and their widespread projections to hypothalamic regions and the spinal cord (Sevigny et al., 2012) are indicative of their central 
role in regulating autonomic, neuroendocrine and behavioral responses to glucoprivation. Comparison of Fos-immunoreactivity after 2DG-induced glucoprivation and hydralazineinduced hypotension in C3 neurons (Menuet et al., 2014) revealed that C3 neurons are selectively activated by 2DG-induced glucoprivation and not by hypotension.

We also found here that some of the PNMT-positive C2 neurons in the rostral NTS were Fos-positive after insulin treatment. This finding agrees with earlier studies using 2DGinduced glucoprivation (Ritter et al., 1998) or insulin-induced hypoglycemia (Yuan \& Yang, 2002), which suggested that the C2 neurons may also play a role in glucose homeostasis. Medullary adrenergic neurons play a vital role in eliciting release of adrenaline from the adrenal medulla in response to glucose deprivation. Stimulation of the RVLM or disinhibition of RVLM neurons with a GABA ${ }_{A}$ receptor antagonist produced hyperglycemic responses (Morrison \& Cao, 2000; Verberne \& Sartor, 2010). Recently, optogenetic stimulation of channelrhodopsin-transfected ventrolateral medullary catecholamine neurons has been shown to evoke hyperglycemia (Zhao et al., 2017). The same study also showed that the hyperglycemic response to a physical stressor was eliminated by ablation of the $\mathrm{C} 1$ population via a Cre-dependent AAV encoding a modified Casp3 gene under the control of the dopamine- $\beta$-hydroxylase promoter (Zhao et al., 2017). Studies combining double labelling immunohistochemistry with retrograde tracing, viral transynaptic tracing or viral vector-mediated expression of green fluorescent protein have shown that some of the $\mathrm{C} 1$ and C3 neurons send axons to the intermediolateral column of the thoracic spinal cord (Card et al., 2006; Minson, Llewellyn-Smith, Neville, Somogyi, \& Chalmers, 1990; Sawchenko \& Bohn, 1989; Sevigny et al., 2012; Strack \& Loewy, 1990; Strack, Sawyer, Hughes, Platt, \& Loewy, 1989; Strack, Sawyer, Platt, \& Loewy, 1989). Furthermore, selective destruction of catecholaminergic neurons through administration of $\mathrm{D} \beta \mathrm{H}$-saporin into the spinal cord destroyed C1 neurons (Madden et al., 2006; Ritter et al., 2001; Schreihofer \& Guyenet, 
2000) and some of the C3 neurons (Ritter et al., 2001; Schreihofer \& Guyenet, 2000). Additionally, the SPN that innervate the adrenal medullary chromaffin cells originate mainly from thoracic segment T4 - T10 of the rat spinal cord (Strack, Sawyer, Marubio, \& Loewy, 1988) and 2DG-induced glucoprivation induced Fos expression in ChAT-positive SPN in these same spinal cord segments (Parker et al., 2013; Ritter et al., 1995).

\subsection{RVLM neurons that respond to metabolic versus cardiovascular stimuli}

C1 Neurons: Some of the C1 neurons in the RVLM are barosensitive and produce Fos in response to hypotension induced by treatment with nitroprusside (Burman et al., 2004; Chan \& Sawchenko, 1994; Minson et al., 1996) or hydralazine (Madden et al., 2006; Nedoboy et al., 2016; Stornetta, Schreihofer, Pelaez, Sevigny, \& Guyenet, 2001; Sved et al., 1994). Indeed, the barosensitive C1 neurons are concentrated immediately caudal to the caudal pole of FN (Chan \& Sawchenko, 1998; Graham, Hoffman, \& Sved, 1995) and this study has identified a significant population of insulin-activated C1 neurons in the same region. Furthermore, disinhibition of RVLM neurons produces not only hyperglycemia but also cardiovascular responses (Verberne \& Sartor, 2010). These data indicate that the neurons controlling cardiovascular and glucoregulatory responses coexist within the RVLM. However, whether the population of RVLM neurons controlling cardiovascular responses is distinct from the population involved in glucose counterregulation has not yet been resolved. Observations made here suggest a trend for insulin-sensitive C1 RVLM neurons to be located in the medial and middle portions of the $\mathrm{C} 1$ column whereas our experience is that hypotension-sensitive C1 RVLM neurons localized with the same anti-Fos antibody often occur in lateral parts of the column (for example, Burman et al., 2004; Chan \& Sawchenko, 1994; Minson et al., 1996). Arguing against the existence of distinct populations of RVLM C1 neurons that respond to metabolic versus cardiovascular stimuli is a recent comparison of 
the neurochemical phenotypes of neurons in the ventrolateral medulla that were activated by hydralazine versus 2DG (Parker et al., 2015; Parker et al., 2017). This analysis suggested that at least some of the RVLM neurons were activated by both stimuli. One explanation for Parker et al.'s finding could be the ability of RVLM neurons to respond to stimulation of cardiopulmonary receptors. While glucoprivation-sensitive adrenal SPN are not barosensitive (Cao \& Morrison, 2001), they do respond to activation of cardiopulmonary receptors (Cao \& Morrison, 2000), implying the existence of a distinct set of RVLM neurons that are not barosensitive but respond to this type of activation. Therefore, it is possible that hydralazine unloads the cardiopulmonary receptors, thereby activating RVLM neurons that control adrenaline secretion. Indeed, plasma adrenaline has been shown to increase following hydralazine administration (Vollmer, Balcita-Pedicino, Debnam, \& Edwards, 2000). Another possible reason for Parker et al's $(2015,2017)$ finding that C1 neurons respond to more than one stimulus is that C1 neurons are interconnected (Agassandian, Shan, Raizada, Sved, \& Card, 2012). Because Fos is a poor marker for timing of activation, a connection between a "cardiovascular" C1 neuron and a "glucoregulatory" C1 neuron could lead to Fos expression in a 2DG-responsive C1 neuron when a hydralazine-responsive C1 neuron is activated. In addition to their cardiovascular and glucoregulatory roles, C1 neurons are also involved in a range of physiological process, such as neuroendocrine responses to infection and inflammation, reproduction, respiratory control, feeding responses, thermoregulation and stress responses mediated by the HPA axis (Guyenet et al., 2013). Exactly how functionally distinct populations of RVLM C1 neurons relate to each other and to populations of RVLM C1 neurons defined on the basis of their neurochemistry is still poorly understood and will provide a fertile area for future research.

Non-C1 Neurons: Falls in blood pressure activate a significant number of non-C1 neurons in the RVLM (Burman et al., 2004; Parker et al., 2017; Schreihofer \& Guyenet, 
1997), implicating them in cardiovascular control. We have found previously that, in the RVLM, non-C1 neurons identified by the fast conduction velocities of their spinal axons do not respond to 2DG (Verberne \& Sartor, 2010). Here, we found that both insulin and saline treatment evoked Fos expression in very variable numbers of PNMT-negative (non-C1) neurons in the RVLM and that the numbers of Fos-positive/PNMT-negative neurons did not vary between the two treatment groups. These results are consistent with the conclusion that RVLM non-C1 neurons do not respond to insulin treatment and therefore may not play a significant role in glucoregulatory responses. In contrast, Parker et al have reported that treatment with 2DG induces Fos synthesis in a significant number of non-C1 neurons (Parker et al., 2015; Parker et al., 2017). There are several possible methodological causes for the divergence between our Fos results with insulin and those of Parker et al with 2DG. First, as discussed above, 2DG and insulin produce quite different physiological stimuli, in particular, hyperglycemia with 2DG versus hypoglycemia with insulin. Second, the extent of food deprivation could affect Fos responses. Our rats were fasted overnight with free access to water whereas Parker et al's rats were deprived of food and water only for the 2 hours between 2DG administration and perfusion. We have chosen to fast animals overnight because we have found that blood glucose readings are more consistent after an overnight compared to a brief fast (Senthilkumaran et al., 2016). Finally, non-C1 neurons in the RVLM can respond to stress by synthesizing Fos. Both air jet stress and conditioned fear have been shown to evoke Fos expression in non-C1 neurons (Carrive \& Gorissen, 2008; Furlong, McDowall, Horiuchi, Polson, \& Dampney, 2014). It is not possible to determine whether stress contributed to the differential Fos response to 2DG versus saline in studies by Parker et al $(2015,2017)$. However, we found here that there was no statistically significant difference between the numbers of Fos-positive/PNMT-negative neurons in insulin- versus saline-treated rats but that the variability in the number of Fos-expressing non-C1 neurons 
between individual rats was high. These results are consistent with activation of Fos by stress in non-C1 neurons.

\subsection{Insulin-responsive DMV neurons}

In confirmation of previous work (Yuan \& Yang, 2002), we found that a large population of vagal motor neurons in the DMV also responded to insulin-induced hypoglycemia by synthesizing Fos. In addition, our study has revealed that the insulinresponsive DMV neurons are concentrated in the medial and middle portions of the DMV beneath and rostral to the area postrema and rarely occur in the lateral DMV. The distribution of the ChAT-positive DMV neurons that express Fos after insulin injection is similar to that of cholinergic DMV neurons that responded to 2DG-induced glucoprivation (Llewellyn-Smith et al., 2012). However, roughly one third of the ChAT-immunoreactive DMV neurons responded to insulin-induced hypoglycemia whereas a total of only 173 ChAT-positive DMV neurons in 5 rats were Fos-positive after administration of 2DG. One possible reason for this difference in activation is that insulin produces a sustained glucoprivic effect whereas 2DG causes the release of counter-regulatory hormones, leading to hyperglycemia that would compete with the glucoprivic effect of 2DG.

Bilaterally-distributed medial DMV neurons innervate the stomach, duodenum and pancreas and are involved in regulating insulin and glucagon secretion from the pancreas and gastric acid secretion (Berthoud, Fox, \& Powley, 1990). A reduction in insulin secretion and an increase in glucagon secretion provide the first line of defense against falling blood glucose levels. Thus, the large number of Fos/ChAT DMV neurons and their distribution documented in this study indicate that administration of insulin most likely activates DMV neurons that innervate the stomach, duodenum and pancreas, which could strongly influence gastrointestinal tract responses during insulin-induced hypoglycemia. In fact, Fos-

This article is protected by copyright. All rights reserved. 
immunoreactivity can be detected in myenteric neurons in the stomach and duodenum after insulin treatment (Yuan \& Yang, 2002), supporting the documented role of DMV neurons in regulating gastrointestinal motility (Rogers, Hermann, \& Travagli, 1999). Physiological and anatomical evidence also suggests that output from DMV neurons affects hepatic glucose metabolism. Vagal nerve stimulation promotes glucose uptake (Pagliassotti \& Cherrington, 1992) while vagal blockade inhibits glycogen synthesis (Cardin, Walmsley, Neal, Williams, \& Cherrington, 2002). Furthermore, neurons in the DMV retrogradely transport horseradish peroxidase from injections into the hepatic branch of the vagus (Norgren \& Smith, 1988) and anterograde tracing from the DMV labels axons in the liver (Berthoud, Kressel, \& Neuhuber, 1992). Hence, an insulin-activated circuit from the DMV to the liver could also help to raise blood glucose in response to insulin-induced hypoglycemia.

DMV neurons are innervated by RVLM C1 neurons (Card et al., 2006; DePuy et al., 2013) and by NTS neurons, which, in turn, receive input from the viscera. The DMV also receives oxytocin innervation from paraventricular nucleus of the hypothalamus (LlewellynSmith et al., 2012), one of the glucoresponsive hypothalamic structures, and from orexincontaining neurons of the perifornical hypothalamus (Date, Ueta, Yamashita, \& Yamaguchi, 1999). Intracerebroventricular injection of orexin induced Fos expression in the DMV (Date et al., 1999). Orexin injections into the DMV increased the discharge of the pancreatic vagal nerve while the increase in pancreatic vagal nerve discharge in response to insulin-induced hypoglycemia was reduced by microinjection of an orexin type 1 receptor antagonist into the DMV (Wu, Gao, Yan, Owyang, \& Li, 2004), implicating the orexinergic input to DMV in the pancreatic response to insulin injection. It would be interesting to investigate whether defects in the responses of cholinergic DMV neurons are involved in the pathophysiological changes in insulin and glucagon secretion in diabetic patients. 
In conclusion, adrenergic C1 and C3 neurons as well as cholinergic vagal motor neurons in the DMV are activated by insulin-induced hypoglycemia. The number of these neurons that express Fos after insulin treatment highlights their vital role in mediating the adrenomedullary, pancreatic and gastrointestinal responses to glucose deprivation. This study has also suggested that, in the RVLM, the topographic distributions of C1 neurons that respond to cardiovascular stimuli versus metabolic stimuli may be different. The RVLM is topographically organized in other species (McAllen \& Dampney, 1990; Ootsuka \& Terui, 1997). Further studies comparing the distribution of the RVLM C1 neurons that respond to these different stimuli will be required to confirm whether this is the case in the rat. 


\section{REFERENCES}

Agassandian, K., Shan, Z., Raizada, M., Sved, A. F., \& Card, J. P. (2012). C1 Catecholamine Neurons form Local Circuit Synaptic Connections Within the Rostroventrolateral Medulla of Rat. Neuroscience, 227, 247-259. doi:10.1016/j.neuroscience.2012.09.049

Arbelaez, A. M., Xing, D., Cryer, P. E., Kollman, C., Beck, R. W., Sherr, J., . . . Tsalikian, E. (2014). Blunted glucagon but not epinephrine responses to hypoglycemia occurs in youth with less than $1 \mathrm{yr}$ duration of type 1 diabetes mellitus. Pediatric diabetes, 15(2), 127-134. doi:10.1111/pedi.12070

Berthoud, H. R., Fox, E. A., \& Powley, T. L. (1990). Localization of vagal preganglionics that stimulate insulin and glucagon secretion. American Journal of Physiology Regulatory, Integrative and Comparative Physiology, 258(1 Pt 2), R160-168. doi:Retrieved from http://ajpregu.physiology.org/content/258/1/R160

Berthoud, H. R., Kressel, M., \& Neuhuber, W. L. (1992). An anterograde tracing study of the vagal innervation of rat liver, portal vein and biliary system. Anatomy and Embryology, 186(5), 431-442. doi:10.1007/bf00185458

Bolli, G., De Feo, P., Compagnucci, P., Cartechini, M. G., Angeletti, G., Santeusanio, F., .. . Gerich, J. E. (1983). Abnormal glucose counterregulation in insulin-dependent diabetes mellitus: interaction of anti-insulin antibodies and impaired glucagon and epinephrine secretion. Diabetes, 32(2), 134-141. doi:https://doi.org/10.2337/diab.32.2.134

This article is protected by copyright. All rights reserved. 
Briski, K. P., \& Sylvester, P. W. (2001). Hypothalamic orexin-A-immunpositive neurons express Fos in response to central glucopenia. Neuroreport, 12(3), 531-534. doi:Retrieved from https://www.ncbi.nlm.nih.gov/pubmed/11234758

Burman, K. J., Sartor, D. M., Verberne, A. J., \& Llewellyn-Smith, I. J. (2004). Cocaine-and amphetamine-regulated transcript in catecholamine and noncatecholamine presympathetic vasomotor neurons of rat rostral ventrolateral medulla. The Journal of comparative neurology, 476(1), 19-31. doi: 10.1002/cne.20198

Cai, X. J., Evans, M. L., Lister, C. A., Leslie, R. A., Arch, J. R., Wilson, S., \& Williams, G. (2001). Hypoglycemia activates orexin neurons and selectively increases hypothalamic orexin-B levels: responses inhibited by feeding and possibly mediated by the nucleus of the solitary tract. Diabetes, 50(1), 105-112. doi:https://doi.org/10.2337/diabetes.50.1.105

Cao, W. H., \& Morrison, S. F. (2000). Responses of adrenal sympathetic preganglionic neurons to stimulation of cardiopulmonary receptors. Brain Research, 887(1), 46-52. doi:https://doi.org/10.1016/S0006-8993(00)02964-4

Cao, W. H., \& Morrison, S. F. (2001). Differential chemoreceptor reflex responses of adrenal preganglionic neurons. American Journal of Physiology - Regulatory, Integrative and Comparative Physiology, 281(6), R1825-1832. doi:Retrieved from http://ajpregu.physiology.org/content/281/6/R1825.long

Card, J. P., Sved, J. C., Craig, B., Raizada, M., Vazquez, J., \& Sved, A. F. (2006). Efferent projections of rat rostroventrolateral medulla C1 catecholamine neurons: Implications

This article is protected by copyright. All rights reserved. 
for the central control of cardiovascular regulation. The Journal of comparative neurology, 499(5), 840-859. doi:10.1002/cne.21140

Cardin, S., Walmsley, K., Neal, D. W., Williams, P. E., \& Cherrington, A. D. (2002). Involvement of the vagus nerves in the regulation of basal hepatic glucose production in conscious dogs. Am J Physiol Endocrinol Metab, 283(5), E958-964. doi:10.1152/ajpendo.00566.2001

Carlton, S. M., Honda, C. N., \& Denoroy, L. (1989). Distribution of phenylethanolamine Nmethyltransferase cell bodies, axons, and terminals in monkey brainstem: an immunohistochemical mapping study. The Journal of comparative neurology, 287(3), 273-285. doi:10.1002/cne.902870302

Carlton, S. M., Honda, C. N., Denoroy, L., \& Willis Jr, W. D. (1987). Descending phenylethanolamine-N-methyltransferase projections to the monkey spinal cord: an immunohistochemical double labeling study. Neuroscience Letters, 76(2), 133-139. doi:https://doi.org/10.1016/0304-3940(87)90704-X

Carrive, P., \& Gorissen, M. (2008). Premotor sympathetic neurons of conditioned fear in the rat. European journal of Neuroscience, 28(3), 428-446. doi:10.1111/j.14609568.2008.06351.x

Chan, R. K., \& Sawchenko, P. E. (1994). Spatially and temporally differentiated patterns of cfos expression in brainstem catecholaminergic cell groups induced by cardiovascular challenges in the rat. The Journal of comparative neurology, 348(3), 433-460. doi:10.1002/cne.903480309

This article is protected by copyright. All rights reserved. 
Chan, R. K., \& Sawchenko, P. E. (1998). Organization and transmitter specificity of medullary neurons activated by sustained hypertension: implications for understanding baroreceptor reflex circuitry. The Journal of Neuroscience, 18(1), 371387. doi:Retrieved from http://www.jneurosci.org/content/18/1/371.long

Cryer, P. E. (2014). Glycemic Goals in Diabetes: Trade-off Between Glycemic Control and latrogenic Hypoglycemia. Diabetes, 63(7), 2188-2195. doi:10.2337/db14-0059

Cryer, P. E., Axelrod, L., Grossman, A. B., Heller, S. R., Montori, V. M., Seaquist, E. R., \& Service, F. J. (2009). Evaluation and Management of Adult Hypoglycemic Disorders: An Endocrine Society Clinical Practice Guideline. The Journal of Clinical Endocrinology \& Metabolism, 94(3), 709-728. doi:10.1210/jc.2008-1410

Damanhuri, H. A., Burke, P. G., Ong, L. K., Bobrovskaya, L., Dickson, P. W., Dunkley, P. R., \& Goodchild, A. K. (2012). Tyrosine hydroxylase phosphorylation in catecholaminergic brain regions: a marker of activation following acute hypotension and glucoprivation. PLoS One, 7(11), e50535. doi:10.1371/journal.pone.0050535

Date, Y., Ueta, Y., Yamashita, H., \& Yamaguchi, H. (1999). Orexins, orexigenic hypothalamic peptides, interact with autonomic, neuroendocrine and neuroregulatory systems. Proceedings of the National Academy of Sciences of the United States of America, 96(2), 748-753. doi:10.1073/pnas.96.2.748

DePuy, S. D., Stornetta, R. L., Bochorishvili, G., Deisseroth, K., Witten, I., Coates, M., \& Guyenet, P. G. (2013). Glutamatergic neurotransmission between the C1 neurons and the parasympathetic preganglionic neurons of the dorsal motor nucleus of the

This article is protected by copyright. All rights reserved. 
vagus. The Journal of Neuroscience, 33(4), 1486-1497. doi:10.1523/jneurosci.426912.2013

Fenwick, N. M., Martin, C. L., \& Llewellyn-Smith, I. J. (2006). Immunoreactivity for cocaineand amphetamine-regulated transcript in rat sympathetic preganglionic neurons projecting to sympathetic ganglia and the adrenal medulla. The Journal of comparative neurology, 495(4), 422-433. doi:10.1002/cne.20870

Furlong, T. M., McDowall, L. M., Horiuchi, J., Polson, J. W., \& Dampney, R. A. (2014). The effect of air puff stress on c-Fos expression in rat hypothalamus and brainstem: central circuitry mediating sympathoexcitation and baroreflex resetting. European Journal of Neuroscience, 39(9), 1429-1438. doi:10.1111/ejn.12521

Garcia, C., Denoroy, L., Le Cavorsin, M., Pujol, J. F., \& Weissmann, D. (1996). Pharmacological modulations of adrenergic phenotype in medullary C2 and C3 cell groups of adult rat. Journal of Chemical Neuroanatomy, 11(2), 131-142. doi:https://doi.org/10.1016/0891-0618(96)00152-4

Gerich, J. E., Langlois, M., Noacco, C., Karam, J. H., \& Forsham, P. H. (1973). Lack of glucagon response to hypoglycemia in diabetes: evidence for an intrinsic pancreatic alpha cell defect. Science, 182(4108), 171-173. doi:https://doi.org/10.1126/science.182.4108.171

Graham, J. C., Hoffman, G. E., \& Sved, A. F. (1995). c-Fos expression in brain in response to hypotension and hypertension in conscious rats. Journal of the Autonomic Nervous System, 55(1-2), 92-104. doi:https://doi.org/10.1016/0165-1838(95)00032-S

This article is protected by copyright. All rights reserved. 
Guyenet, P. G., Stornetta, R. L., Bochorishvili, G., Depuy, S. D., Burke, P. G., \& Abbott, S. B. (2013). C1 neurons: the body's EMTs. American Journal of Physiology - Regulatory, Integrative and Comparative Physiology, 305(3), R187-204. doi:10.1152/ajpregu.00054.2013

Hudson, B., \& Ritter, S. (2004). Hindbrain catecholamine neurons mediate consummatory responses to glucoprivation. Physiology \& Behavior, 82(2-3), 241-250. doi:https://doi.org/10.1016/j.physbeh.2004.03.032

Kerman, I. A., Bernard, R., Rosenthal, D., Beals, J., Akil, H., \& Watson, S. J. (2007). Distinct populations of presympathetic-premotor neurons express orexin or melaninconcentrating hormone in the rat lateral hypothalamus. The Journal of comparative neurology, 505(5), 586-601. doi:10.1002/cne.21511

Kitahama, K., Denoroy, L., Berod, A., \& Jouvet, M. (1986). Distribution of PNMTimmunoreactive neurons in the cat medulla oblongata. Brain Research Bulletin, 17(2), 197-208. doi:https://doi.org/10.1016/0361-9230(86)90116-4

Kitahama, K., Pearson, J., Denoroy, L., Kopp, N., Ulrich, J., Maeda, T., \& Jouvet, M. (1985). Adrenergic neurons in human brain demonstrated by immunohistochemistry with antibodies to phenylethanolamine-N-methyltransferase (PNMT): Discovery of a new group in the nucleus tractus solitarius. Neuroscience Letters, 53(3), 303-308. doi:https://doi.org/10.1016/0304-3940(85)90555-5

Korim, W. S., Bou Farah, L., McMullan, S., \& Verberne, A. J. (2014). Orexinergic activation of medullary premotor neurons modulates the adrenal sympathoexcitation to hypothalamic glucoprivation. Diabetes, 63(6), 1895-1906. doi:10.2337/db13-1073

This article is protected by copyright. All rights reserved. 
Korim, W. S., Llewellyn-Smith, I. J., \& Verberne, A. J. (2016). Activation of MedullaProjecting Perifornical Neurons Modulates the Adrenal Sympathetic Response to Hypoglycemia: Involvement of Orexin Type 2 (OX2-R) Receptors. Endocrinology, 157(2), 810-819. doi:10.1210/en.2015-1712

Li, A.-J., Wang, Q., Dinh, T. T., \& Ritter, S. (2009). Simultaneous silencing of Npy and Dbh expression in hindbrain A1/C1 catecholamine cells suppresses glucoprivic feeding. The Journal of Neuroscience, 29(1), 280-287. doi:10.1523/JNEUROSCI.426708.2009.

Li, A.-J., Wang, Q., Elsarelli, M. M., Brown, R. L., \& Ritter, S. (2015). Hindbrain Catecholamine Neurons Activate Orexin Neurons During Systemic Glucoprivation in Male Rats. Endocrinology, 156(8), 2807-2820. doi:10.1210/en.2015-1138

Li, A.-J., Wang, Q., \& Ritter, S. (2011). Participation of Hindbrain AMP-Activated Protein Kinase in Glucoprivic Feeding. Diabetes, 60(2), 436-442. doi:10.2337/db10-0352

Llewellyn-Smith, I. J., Gnanamanickam, G. J. E., Reimann, F., Gribble, F. M., \& Trapp, S. (2013). Preproglucagon (PPG) neurons innervate neurochemically identified autonomic neurons in the mouse brainstem. Neuroscience, 229, 130-143. doi:https://doi.org/10.1016/j.neuroscience.2012.09.071

Llewellyn-Smith, I. J., Kellett, D. O., Jordan, D., Browning, K. N., \& Travagli, R. A. (2012). Oxytocin-immunoreactive innervation of identified neurons in the rat dorsal vagal complex. Neurogastroenterology \& Motility, 24(3), e136-146. doi:10.1111/j.13652982.2011.01851.x

This article is protected by copyright. All rights reserved. 
Llewellyn-Smith, I. J., DiCarlo, S. E., Collins, H. L., \& Keast, J. R. (2005). Enkephalinimmunoreactive interneurons extensively innervate sympathetic preganglionic neurons regulating the pelvic viscera. The Journal of comparative neurology, 488(3), 278-289. doi:10.1002/cne.20552

Llewellyn-Smith, I. J., Martin, C. L., Fenwick, N. M., Dicarlo, S. E., Lujan, H. L., \& Schreihofer, A. M. (2007). VGLUT1 and VGLUT2 innervation in autonomic regions of intact and transected rat spinal cord. The Journal of comparative neurology, 503(6), 741-767. doi:DOI: 10.1002/cne.21414

Madden, C. J., Stocker, S. D., \& Sved, A. F. (2006). Attenuation of homeostatic responses to hypotension and glucoprivation after destruction of catecholaminergic rostral ventrolateral medulla neurons. American Journal of Physiology - Regulatory Integrative \& Comparative Physiology, 291(3), R751-759.

doi:10.1152/ajpregu.00800.2005

McAllen, R. M., \& Dampney, R. A. L. (1990). Vasomotor neurons in the rostral ventrolateral medulla are organized topographically with respect to type of vascular bed but not body region. Neuroscience Letters, 110(1), 91-96. doi:http://dx.doi.org/10.1016/0304$\underline{3940(90) 90793-9}$

Menuet, C., Sevigny, C. P., Connelly, A. A., Bassi, J. K., Jancovski, N., Williams, D. A., . . Allen, A. M. (2014). Catecholaminergic C3 neurons are sympathoexcitatory and involved in glucose homeostasis. The Journal of Neuroscience, 34(45), 15110-15122. doi:https://doi.org/10.1523/JNEUROSCI.3179-14.2014

This article is protected by copyright. All rights reserved. 
Minson, J., Arnolda, L., Llewellyn-Smith, I., Pilowsky, P., \& Chalmers, J. (1996). Altered c-fos in rostral medulla and spinal cord of spontaneously hypertensive rats. Hypertension, 27(3), 433-441. doi:https://doi.org/10.1161/01.HYP.27.3.433

Minson, J., Llewellyn-Smith, I., Neville, A., Somogyi, P., \& Chalmers, J. (1990). Quantitative analysis of spinally projecting adrenaline-synthesising neurons of C1, C2 and C3 groups in rat medulla oblongata. Journal of the autonomic nervous system, 30(3), 209-220. doi:https://doi.org/10.1016/0165-1838(90)90252-E

Mittendorf, A., Denoroy, L., \& Flugge, G. (1988). Anatomy of the adrenergic system in the medulla oblongata of the tree shrew: PNMT immunoreactive structures within the nucleus tractus solitarii. The Journal of comparative neurology, 274(2), 178-189. doi:10.1002/cne.902740205

Morrison, S. F., \& Cao, W. H. (2000). Different adrenal sympathetic preganglionic neurons regulate epinephrine and norepinephrine secretion. American Journal of Physiology Regulatory, Integrative and Comparative Physiology, 279(5), R1763-1775. doi:Retrieved from http://ajpregu.physiology.org/content/279/5/R1763

Mueller, P. J., Mischel, N. A., \& Scislo, T. J. (2011). Differential activation of adrenal, renal, and lumbar sympathetic nerves following stimulation of the rostral ventrolateral medulla of the rat. American Journal of Physiology - Regulatory, Integrative and Comparative Physiology, 300(5), R1230-R1240. doi:10.1152/ajpregu.00713.2010

Mussa, B. M., \& Verberne, A. J. (2013). The dorsal motor nucleus of the vagus and regulation of pancreatic secretory function. Experimental Physiology, 98(1), 25-37. doi:10.1113/expphysiol.2012.066472

This article is protected by copyright. All rights reserved. 
Nedoboy, P. E., Mohammed, S., Kapoor, K., Bhandare, A. M., Farnham, M. M., \& Pilowsky, P. M. (2016). pSer40 tyrosine hydroxylase immunohistochemistry identifies the anatomical location of C1 neurons in rat RVLM that are activated by hypotension. Neuroscience, 317, 162-172. doi:10.1016/j.neuroscience.2016.01.012

Norgren, R., \& Smith, G. P. (1988). Central distribution of subdiaphragmatic vagal branches in the rat. The Journal of comparative neurology, 273(2), 207-223. doi:10.1002/cne.902730206

Ootsuka, Y., \& Terui, N. (1997). Functionally different neurons are organized topographically in the rostral ventrolateral medulla of rabbits. Journal of the Autonomic Nervous System, 67(1), 67-78. doi:http://dx.doi.org/10.1016/S0165-1838(97)00094-5

Pagliassotti, M. J., \& Cherrington, A. D. (1992). Regulation of net hepatic glucose uptake in vivo. Annual review of physiology, 54, 847-860.

doi:10.1146/annurev.ph.54.030192.004215

Parker, L. M., Kumar, N. N., Lonergan, T., \& Goodchild, A. K. (2013). Neurochemical codes of sympathetic preganglionic neurons activated by glucoprivation. The Journal of comparative neurology, 521(12), 2703-2718. doi:10.1002/cne.23310.

Parker, L. M., Kumar, N. N., Lonergan, T., McMullan, S., \& Goodchild, A. K. (2015). Distribution and neurochemical characterization of neurons in the rat ventrolateral medulla activated by glucoprivation. Brain Structure and Function, 220(1), 117-134. doi:10.1007/s00429-013-0642-3

Parker, L. M., Le, S., Wearne, T. A., Hardwick, K., Kumar, N. N., Robinson, K. J., . . . Goodchild, A. K. (2017). Neurochemistry of neurons in the ventrolateral medulla 
activated by hypotension: Are the same neurons activated by glucoprivation? The Journal of comparative neurology, 525(9), 2249-2264. doi:10.1002/cne.24203

Pierce, R. A., Sandefur, S., Doyle, G. A., \& Welgus, H. G. (1996). Monocytic cell typespecific transcriptional induction of collagenase. The Journal of clinical investigation, 97(8), 1890-1899. doi:10.1172/jci118620

Ritter, S., Bugarith, K., \& Dinh, T. T. (2001). Immunotoxic destruction of distinct catecholamine subgroups produces selective impairment of glucoregulatory responses and neuronal activation. The Journal of comparative neurology, 432(2), 197-216. doi:10.1002/cne.1097

Ritter, S., Dinh, T. T., \& Li, A. J. (2006). Hindbrain catecholamine neurons control multiple glucoregulatory responses. Physiology \& Behavior, 89(4), 490-500. doi:10.1016/j.physbeh.2006.05.036

Ritter, S., Llewellyn-Smith, I., \& Dinh, T. T. (1998). Subgroups of hindbrain catecholamine neurons are selectively activated by 2-deoxy-d-glucose induced metabolic challenge. Brain Research, 805(1-2), 41-54. doi:10.1016/s0006-8993(98)00655-6

Ritter, S., Scheurink, A., \& Singer, L. K. (1995). 2-Deoxy-D-Glucose but not 2Mercaptoacetate Increases Fos-Like Immunoreactivity in Adrenal Medulla and Sympathetic Preganglionic Neurons. Obesity Research, 3(S5), 729S-734S. doi:10.1002/j.1550-8528.1995.tb00492.x

Rogers, R. C., Hermann, G. E., \& Travagli, R. A. (1999). Brainstem pathways responsible for oesophageal control of gastric motility and tone in the rat. J Physiol, 514 ( Pt 2), 369383. doi:10.1111/j.1469-7793.1999.369ae.x

This article is protected by copyright. All rights reserved. 
Sawchenko, P. E., \& Bohn, M. C. (1989). Glucocorticoid receptor-immunoreactivity in C1, $\mathrm{C} 2$, and $\mathrm{C} 3$ adrenergic neurons that project to the hypothalamus or to the spinal cord in the rat. The Journal of comparative neurology, 285(1), 107-116. doi:10.1002/cne.902850109

Schindelin, J., Arganda-Carreras, I., Frise, E., Kaynig, V., Longair, M., Pietzsch, T., . . . Schmid, B. (2012). Fiji: an open-source platform for biological-image analysis. Nature methods, 9(7), 676-682. doi:10.1038/nmeth.2019

Schreihofer, A. M., \& Guyenet, P. G. (1997). Identification of C1 presympathetic neurons in rat rostral ventrolateral medulla by juxtacellular labeling in vivo. The Journal of comparative neurology, 387(4), 524-536. doi:10.1002/(SICI)10969861(19971103)387:4<524::AID-CNE4>3.0.CO;2-4

Schreihofer, A. M., \& Guyenet, P. G. (2000). Sympathetic reflexes after depletion of bulbospinal catecholaminergic neurons with anti-DbetaH-saporin. American Journal of Physiology - Regulatory, Integrative and Comparative Physiology, 279(2), R729742. doi:Retrieved from http://ajpregu.physiology.org/content/279/2/R729.long

Senthilkumaran, M., Johnson, M. E., \& Bobrovskaya, L. (2016). The effects of insulininduced hypoglycaemia on tyrosine hydroxylase phosphorylation in rat brain and adrenal gland. Neurochemical research, 41(7), 1612-1624. doi:10.1007/s11064-0161875-3.

Sevigny, C. P., Bassi, J., Williams, D. A., Anderson, C. R., Thomas, W. G., \& Allen, A. M. (2012). Efferent projections of C3 adrenergic neurons in the rat central nervous 
system. The Journal of comparative neurology, 520(11), 2352-2368.

doi:10.1002/cne.23041

Siafarikas, A., Johnston, R. J., Bulsara, M. K., O'leary, P., Jones, T. W., \& Davis, E. A. (2012). Early loss of the glucagon response to hypoglycemia in adolescents with type 1 diabetes. Diabetes Care, 35(8), 1757-1762. doi:https://doi.org/10.2337/dc11-2010

Siaud, P., Denoroy, L., Assenmacher, I., \& Alonso, G. (1989). Comparative immunocytochemical study of the catecholaminergic and peptidergic afferent innervation to the dorsal vagal complex in rat and guinea pig. The Journal of comparative neurology, 290(3), 323-335. doi:10.1002/cne.902900302

Smith, R. B., Edwards, J. P., \& Johnston, D. (1981). Effect of vagotomy on exocrine pancreatic and biliary secretion in man. The American Journal of Surgery, 141(1), 4047. doi:http://dx.doi.org/10.1016/0002-9610(81)90009-X

Stornetta, R. L., Akey, P. J., \& Guyenet, P. G. (1999). Location and electrophysiological characterization of rostral medullary adrenergic neurons that contain neuropeptide $Y$ mRNA in rat medulla. The Journal of comparative neurology, 415(4), 482-500. doi:10.1002/(SICI)1096-9861(19991227)415:4<482::AID-CNE5>3.0.CO;2-4

Stornetta, R. L., Schreihofer, A. M., Pelaez, N. M., Sevigny, C. P., \& Guyenet, P. G. (2001). Preproenkephalin mRNA is expressed by $\mathrm{C} 1$ and non-C1 barosensitive bulbospinal neurons in the rostral ventrolateral medulla of the rat. The Journal of Comparative Neurolology, 435(1), 111-126. doi:10.1002/cne.1196

Stornetta, R. L., Sevigny, C. P., Schreihofer, A. M., Rosin, D. L., \& Guyenet, P. G. (2002). Vesicular glutamate transporter DNPI/VGLUT2 is expressed by both C1 adrenergic 
and nonaminergic presympathetic vasomotor neurons of the rat medulla. The Journal of Comparative Neurolology, 444(3), 207-220. doi:10.1002/cne.10142

Strack, A., \& Loewy, A. (1990). Pseudorabies virus: a highly specific transneuronal cell body marker in the sympathetic nervous system. The Journal of Neuroscience, 10(7), 2139-2147. doi:Retrieved from http://www.jneurosci.org/content/10/7/2139.long

Strack, A. M., Sawyer, W. B., Hughes, J. H., Platt, K. B., \& Loewy, A. D. (1989). A general pattern of CNS innervation of the sympathetic outflow demonstrated by transneuronal pseudorabies viral infections. Brain Research, 491(1), 156-162. doi:https://doi.org/10.1016/0006-8993(89)90098-X

Strack, A. M., Sawyer, W. B., Marubio, L. M., \& Loewy, A. D. (1988). Spinal origin of sympathetic preganglionic neurons in the rat. Brain Research, 455(1), 187-191. doi:https://doi.org/10.1016/0006-8993(88)90132-1

Strack, A. M., Sawyer, W. B., Platt, K. B., \& Loewy, A. D. (1989). CNS cell groups regulating the sympathetic outflow to adrenal gland as revealed by transneuronal cell body labelling with pseudorabies virus. Brain Research, 491(2), 274-296. doi:http://dx.doi.org/10.1016/0006-8993(89)90063-2

Sved, A., Mancini, D. L., Graham, J. C., Schreihofer, A., \& Hoffman, G. E. (1994). PNMTcontaining neurons of the $\mathrm{C} 1$ cell group express $\mathrm{c}$-fos in response to changes in baroreceptor input. American Journal of Physiology-Regulatory, Integrative and Comparative Physiology, 266(2), R361-R367. doi:Retrieved from http://ajpregu.physiology.org/content/266/2/R361

This article is protected by copyright. All rights reserved. 
Verberne, A. J., Korim, W. S., Sabetghadam, A., \& Llewellyn-Smith, I. J. (2016). Adrenaline: insights into its metabolic roles in hypoglycaemia and diabetes. British journal of pharmacology, 173(9), 1425-1437. doi:10.1111/bph.13458

Verberne, A. J., Sabetghadam, A., \& Korim, W. S. (2014). Neural pathways that control the glucose counterregulatory response. Frontiers in Neuroscience, 8, 38. doi:10.3389/fnins.2014.00038

Verberne, A. J., \& Sartor, D. M. (2010). Rostroventrolateral medullary neurons modulate glucose homeostasis in the rat. American Journal of Physiology - Endocrinology and Metabolism, 299(5), E802-807. doi:10.1152/ajpendo.00466.2010

Verberne, A. J. M., Stornetta, R. L., \& Guyenet, P. G. (1999). Properties of C1 and other ventrolateral medullary neurones with hypothalamic projections in the rat. J Physiol, 517(Pt 2), 477-494. doi:10.1111/j.1469-7793.1999.0477t.x

Vollmer, R. R., Balcita-Pedicino, J. J., Debnam, A. J., \& Edwards, D. J. (2000). Adrenal medullary catecholamine secretion patterns in rats evoked by reflex and direct neural stimulation. Clinical and Experimental Hypertension, 22(7-8), 705-715. doi:10.1081/CEH-100102002

Vollmer, R. R., Baruchin, A., Kolibal-Pegher, S. S., Corey, S. P., Stricker, E. M., \& Kaplan, B. B. (1992). Selective activation of norepinephrine- and epinephrine-secreting chromaffin cells in rat adrenal medulla. American Journal of Physiology - Regulatory, Integrative and Comparative Physiology, 263(3 Pt 2), R716-721. doi:Retrieved from http://ajpregu.physiology.org/content/263/3/R716

This article is protected by copyright. All rights reserved. 
Wargnier, A., Legros-Maida, S., Bosselut, R., Bourge, J. F., Lafaurie, C., Ghysdael, C. J., . . . Paul, P. (1995). Identification of human granzyme B promoter regulatory elements interacting with activated T-cell-specific proteins: implication of Ikaros and CBF binding sites in promoter activation. Proceedings of the National Academy of Sciences of the United States of America, 92(15), 6930-6934. doi:Retrieved from https://www.ncbi.nlm.nih.gov/pubmed/7624346

Welter, J. F., Crish, J. F., Agarwal, C., \& Eckert, R. L. (1995). Fos-related Antigen (Fra-1), junB, and junD Activate Human Involucrin Promoter Transcription by Binding to Proximal and Distal AP1 Sites to Mediate Phorbol Ester Effects on Promoter Activity. Journal of Biological Chemistry, 270(21), 12614-12622. doi:10.1074/jbc.270.21.12614

Wu, X., Gao, J., Yan, J., Owyang, C., \& Li, Y. (2004). Hypothalamus-brain stem circuitry responsible for vagal efferent signaling to the pancreas evoked by hypoglycemia in rat. Journal of neurophysiology, 91(4), 1734-1747. doi:10.1152/jn.00791.2003

Yettefti, K., Orsini, J.-C., \& Perrin, J. (1997). Characteristics of glycemia-sensitive neurons in the nucleus tractus solitarii: Possible involvement in nutritional regulation. Physiology \& Behavior, 61(1), 93-100. doi:http://dx.doi.org/10.1016/S0031-9384(96)00358-7

Yuan, P.-Q., \& Yang, H. (2002). Neuronal activation of brain vagal-regulatory pathways and upper gut enteric plexuses by insulin hypoglycemia. American Journal of PhysiologyEndocrinology And Metabolism, 283(3), E436-E448. doi:10.1152/ajpendo.00538.2001

Zhao, Z., Wang, L., Gao, W., Hu, F., Zhang, J., Ren, Y., . . Zhan, C. (2017). A Central Catecholaminergic Circuit Controls Blood Glucose Levels during Stress. Neuron, 95(1), 138-152.e135. doi:10.1016/j.neuron.2017.05.031

This article is protected by copyright. All rights reserved. 


\section{FIGURE LEGENDS}

Figure 1. Insulin lowers blood glucose.

Graph showing changes in blood glucose levels after injection of insulin or saline.

Measurements were made on tail vein blood samples taken 5 min prior to injection and at 30, 60 and 90 min after injection. Saline injection did not alter blood glucose levels (grey) whereas insulin injection reduced blood glucose levels within 30 min and levels stayed low until 90 min (black). $n=8$ per group; Data are presented as mean $\pm \mathrm{SEM}$; ${ }^{\star \star \star} P<0.001$.

Figure 2. Adrenergic chromaffin cells in the adrenal gland are activated by insulin but noradrenergic chromaffin cells are not.

a, In insulin-treated rats, almost all of the brown PNMT-immunoreactive chromaffin cells have black Fos-immunoreactive nuclei. b, After saline treatment, none of the PNMTimmunoreactive chromaffin cells show Fos-immunoreactivity. After insulin as well as saline treatment, small clumps of noradrenergic chromaffin cell ${ }^{*}$ ) lack immunoreactivity for both PNMT and Fos. Scale bars, $100 \mu \mathrm{m}$.

Figure 3. Insulin-responsive C1 neurons in the caudal ventrolateral medulla (CVLM).

a, Almost all of the brown PNMT-immunoreactive C1 neurons in the CVLM (section FN-9, $1080 \mu \mathrm{m}$ caudal to the caudal pole of the facial nucleus [FN]) have black Fosimmunoreactive nuclei. The Fos/PNMT neurons indicated by arrows b-d are shown at higher magnification in panels b-d. Other Fos/PNMT neurons are indicated by arrowheads. b-d, Fos/PNMT neurons indicated by arrows b-d in a. Scale bars: $250 \mu \mathrm{m}$ in a, $10 \mu \mathrm{m}$ in b, $20 \mu \mathrm{m}$ in $\mathrm{c}$ and $\mathrm{d}$. 
Figure 4. Insulin-responsive C1 neurons in the rostral ventrolateral medulla (RVLM).

a, Many of the brown PNMT-immunoreactive C1 neurons in the RVLM located just caudal to the caudal pole of the FN (section FN-1, $120 \mu \mathrm{m}$ caudal to the caudal pole of FN) have black Fos-immunoreactive nuclei. However, the proportion of PNMT-stained neurons that express Fos is less than in the CVLM. The Fos/PNMT neurons indicated by arrows $b$ - $d$ are shown at higher magnification in panels b-d. b-d, Fos/PNMT neurons indicated by arrows b-d in a. e, Only a few PNMT-immunoreactive C1 neurons located rostral to the caudal pole of the FN (section FN+2) have black Fos-immunoreactive nuclei. The star indicates FN. f, Fos/PNMT neurons enclosed by the box in e. Scale bars: $250 \mu \mathrm{m}$ in a and e, $20 \mu \mathrm{m}$ in b-d, $50 \mu \mathrm{m}$ in f.

Figure 5. Maps showing the distribution of insulin-responsive C1 neurons in the RVLM.

The most caudal section is at the top left of the figure and the most rostral section is at the bottom right. Fos/PNMT neurons are represented by red dots; and PNMT only neurons, by blue dots. Neurons that are immunoreactive for Fos and PNMT in the rostral portion of the C1 cell column (from FN-4 to FN0) appear to be preferentially located closer to the pyramids in the medial and middle portions of the $\mathrm{C} 1$ cell column rather than in the lateral portion of the column. FN, facial nucleus; NAc, compact formation of the nucleus ambiguus; py, pyramidal tract; IO, inferior olive. Scale bar, $0.5 \mathrm{~mm}$.

Figure 6. Fos-immunoreactivity in C1 neurons after saline treatment.

a, In the CVLM (section FN-7, $840 \mu \mathrm{m}$ caudal to the caudal pole of FN) from a control rat, only two of the brown PNMT-immunoreactive C1 neurons have black Fos-positive nuclei. 
The arrow indicates one of these Fos/PNMT neurons. b, In the RVLM (sections FN-1, 120 $\mu \mathrm{m}$ caudal to the caudal pole of FN) from a control rat, none of the brown PNMT-positive C1 neurons are Fos-positive. Scale bars, $250 \mu \mathrm{m}$.

Figure 7. Insulin-responsive C2 neuron in the nucleus of the solitary tract (NTS). a, A brown PNMT-immunoreactive $\mathrm{C} 2$ neurons in box $\mathrm{b}$ (shown at higher magnification in panel b) lies near the medial edge of the NTS. $\mathbf{b}$, The neuron in box b has a black Fosimmunoreactive nucleus, indicating that it was activated by insulin treatment. $4 \mathrm{~V}, 4^{\text {th }}$ ventricle. Scale bars: $250 \mu \mathrm{m}$ in a, $20 \mu \mathrm{m}$ in b.

\section{Figure 8. Insulin-responsive C3 neurons in the dorsal medulla.}

a \& e, Almost all of the brown PNMT-immunoreactive C3 neurons in this section (section FN$3,360 \mu \mathrm{m}$ caudal to the section containing the caudal pole of FN) have black Fosimmunoreactive nuclei. The Fos/PNMT neurons indicated by arrows $b$ - $d$ and $f$ are shown at higher magnification in panels b-d and f. Other Fos/PNMT neurons are indicated by arrowheads. b-d, Fos/PNMT neurons indicated by arrows b-d in a. f, Fos/PNMT neuron indicated by arrow $\mathrm{f}$ in e. $4 \mathrm{~V}, 4^{\text {th }}$ ventricle; NTS, nucleus of the solitary tract. Scale bars: 250 $\mu \mathrm{m}$ in $\mathrm{a}, 20 \mu \mathrm{m}$ in $\mathrm{b}-\mathrm{d}$ and $\mathrm{F}$ and $100 \mu \mathrm{m}$ in $\mathrm{e}$.

\section{Figure 9. Fos-immunoreactivity in C3 neurons after saline treatment.}

$\mathbf{a} \& \mathbf{b}$, In the dorsal region of section FN-3 from a control rat (360 $\mu$ m caudal to the section containing the caudal pole of FN), none of the brown PNMT-immunoreactive C3 neurons are have Fos-immunoreactive nuclei. $4 \mathrm{~V}, 4^{\text {th }}$ ventricle. Scale bars: $250 \mu \mathrm{m}$ in a, $100 \mu \mathrm{m}$ in $\mathrm{b}$. 


\section{Figure 10. Insulin-responsive dorsal vagal motor (DMV) neurons.}

a, In the DMV at a level equivalent to the middle of the area postrema (360 $\mu \mathrm{m}$ rostral to section that contains the caudal tip of the area postrema, i.e., section AP0), a few of the brown ChAT-immunoreactive DMV neurons have black Fos-immunoreactive nuclei. The Fos/ChAT and ChAT only neurons in this section are counted and mapped at $+360 \mu \mathrm{m}$ in Figure 11. b, In the DMV at a level equivalent to the rostral edge of the AP (600 $\mu \mathrm{m}$ rostral to AP0), almost half of the brown ChAT-immunoreactive DMV neurons have black Fosimmunoreactive nuclei. The Fos/ChAT and ChAT only neurons in this section are counted and mapped at $+720 \mu \mathrm{m}$ in Figure 11. c \& d, About $1.2 \mathrm{~mm}$ rostral to the level at which the central canal opens into the fourth ventricle $(4 \mathrm{~V})$, a few ChAT-immunoreactive neurons in the very rostral DMV have black Fos-immunoreactive nuclei. The Fos/ChAT neurons in the box are shown at higher magnification in panel d. DMV, dorsal motor nucleus of the vagus; NTS, nucleus of the solitary tract; HGN, hypoglossal nucleus; cc, central canal. Scale bars: $100 \mu \mathrm{m}$ in $a$ and $b, 100 \mu \mathrm{m}$ in $\mathrm{c}$ and $50 \mu \mathrm{m}$ in $\mathrm{d}$.

\section{Figure 11. Maps showing the distribution of insulin-responsive neurons in the} dorsal motor nucleus of the vagus (DMV).

The most caudal section (AP0), which contains the caudal tip of the area postrema (AP), is at the top of the left column; the most rostral section is at the bottom of the right column and is located about $1 \mathrm{~mm}$ rostral to where the central canal opens into the fourth ventricle (4V). Fos/ChAT neurons are represented by red dots; and ChAT only neurons, by blue dots. The numbers of Fos/ChAT and ChAT only neurons in each mapped section are shown above the map for that section in red and blue, respectively. ChAT-immunoreactive neurons with Fosimmunoreactive nuclei are most numerous in sections below and just rostral to AP. The 
Fos/ChAT neurons occur in the medial and middle portions of the DMV and are only rarely found in the most lateral DMV region. HGN, hypoglossal nucleus. An asterisk indicates the section through the middle of area postrema, which is shown in Figure 10a. The star indicates the section which contains the rostral edge of the area postrema and is shown in Figure 10b. Scale bar, $100 \mu \mathrm{m}$.

\section{Figure 12. Fos-immunoreactivity in dorsal vagal motor neurons after saline treatment.}

In the dorsal motor nucleus of the vagus (DMV) at the level containing the rostral AP, none of the brown ChAT-immunoreactive neurons have black Fos-immunoreactive nuclei. NTS, nucleus of the solitary tract; HGN, hypoglossal nucleus; cc, central canal. Scale bar, $100 \mu \mathrm{m}$.

\section{Figure 13. Rostrocaudal distribution of insulin-responsive neurons in the RVLM.}

In insulin-treated rats (black line), the number (a) and percentage (b) of Fos/PNMT neurons gradually increased from the caudal end of the area traditionally defined as the RVLM (FN-5, 600 caudal to the caudal pole of FN). The highest number of Fos/PNMT occurred in section $\mathrm{FN}-2$, i.e. within $240 \mu \mathrm{m}$ of the caudal pole of FN. In saline-treated rats (grey line), the numbers of Fos/PNMT neurons in sections FN-5 to FNO was significantly lower than in the insulin-treated rats. Data represented as mean \pm SEM, ${ }^{\star} P<0.05,{ }^{* \star} P<0.01,{ }^{* \star \star} P<0.001$. 


\section{University Library}

\section{- M M N E R VA A gateway to Melbourne's research publications}

Minerva Access is the Institutional Repository of The University of Melbourne

Author/s:

Senthilkumaran, M;Bobrovskaya, L;Verberne, AJM;Llewellyn-Smith, IJ

Title:

Insulin-responsive autonomic neurons in rat medulla oblongata

Date:

2018-11-01

Citation:

Senthilkumaran, M., Bobrovskaya, L., Verberne, A. J. M. \& Llewellyn-Smith, I. J. (2018).

Insulin-responsive autonomic neurons in rat medulla oblongata. [Abstract]. JOURNAL OF COMPARATIVE NEUROLOGY, 526 (16), pp.2665-2682. https://doi.org/10.1002/cne.24523.

Persistent Link:

http://hdl.handle.net/11343/283426 